ORIGINAL ARTICLE

\title{
LYMPH NODE STAGING IN BLADDER CANCER: ROLE OF DIFFUSION WEIGHTED MAGNETIC RESONANT IMAGING COMPARED TO HISTOPATHOLOGY
}

\author{
Mohammed Salah El Din Doraey ${ }^{1}$, Khaled M Abd elwahab ${ }^{1}$, Hossam M Abdel-Rahma ${ }^{2}$, Osama \\ K Kamhawy ${ }^{1}$ and M Alaa Bahy el din ${ }^{1}$
}

1 Department of Urology, Faculty of Medicine, Zagazig University, Sharkia, Egypt

2 Department of Radiology, Faculty of Medicine, Zagazig University, Sharkia, Egypt

Corresponding author

Mohammed Salah El Din EL

Doraey

Department of Urology, Faculty of Medicine, Zagazig University, Sharkia Egypt

mohamed.salah.urology@gmail.com

$\begin{array}{ll}\text { Submit Date } & 2019-03-26 \\ \text { Revise Date } & 2019-04-20 \\ \text { Accept Date } & 2019-04-22\end{array}$

\section{ABSTRACT}

Background : lymph node metastasis is important prognostic factor in bladder cancer paients.It also helps in treatment planning.Diffusion weighted magnetic resonance imaging is a new technique for lymph node evaluation depending on tissue cellurality rather than size of lymph nodes. Purpose : The aim of this work is to study the role of DW_MRI in detecting LNs metastasis and staging in bladder cancer. Methods: The study has been carried out at the department of Urology, Zagazig University Hospitals from July 2016 till December 2018. Results: 33 patients with radical cystectomy and lymphadenectomy whom were evaluated by DW-MRI preoperatively. The overall senstivity of DWMRI was $85.7 \%$ and overall specificty was $94.7 \%$. Conclusion: DWMRI is a safe non invasive technique in lymph node staging in bladder cancer patients with high senstivity and specificty.

Keywords : diffuion weighted magnetic resonance imaging (DW-MRI), bladder cancer, lymphadenectomy, lymph node staging, senstivity and specificty.

\section{INTRODUCTION}

$\mathrm{U}$ rothelial bladder carcinoma is the 7 th commonest cancer in men while it is the 17 th in women along the world. Urothelial carcinoma is more prevalent than squamous carcinoma in developed countries. [1] Radical cystectomy and bilateral lymphadenectomy permit accurate staging and it is the treatment of choice for muscle invasive bladder cancer. [2] CT and MRI are usually used for $\mathrm{LN}$ staging, and it depends on dimensional criteria only. [3] Micro-metastases are present in about $25 \%$ in bladder cancer patient with normal sized lymph nodes on preoperative imaging. Also, enlarged lymph nodes due to inflammatory changes give false positive results. [4] Diffusion weighted MRI is noninvasive technique that visualizes molecular diffusion which is the Brownian motion of water molecules in biological tissues. The mobility depends on cell wall integrity and underlying tissue cellularity. The mobility is quantified by calculating apparent diffusion coefficient, which depends on the choice of underlying $b$ value. [5] The potential ability of differentiation between benign and malignant LNs depending on high cellularity and low ADC (apparent diffusion coefficient) values in malignant lymph nodes done using DW_MRI. [6]

\section{Statistical Analysis:}

Data collected throughout history, basic clinical examination, laboratory investigations and outcome measures coded, entered and analyzed using Microsoft Excel software. Data were then imported into Statistical Package for the Social Sciences (SPSS version 20.0) (Statistical Package for the Social Sciences) software for analysis. According to the type of data qualitative represent as number and percentage, quantitative continues group represent by mean $\pm \mathrm{SD}$, the following tests were used to test differences for significance. difference and association of qualitative variable by $\mathrm{Chi}$ square test $\left(\mathrm{X}^{2}\right)$. Agreement by Kappa. P 
value was set at $<0.05$ for significant results $\&<0.001$ for high significant result.

\section{METHODS}

In the current prospective study 33 patients with muscle invasive bladder cancer underwent radical cystectomy and standard pelvic lymphadenectomy: the upper limit is common iliac artery, the inferior limit is lymph node of Cloquet, the lateral limit is genitofemoral nerve and the posterior limit is internal iliac artery. The preoperative imaging was DW-MRI on pelvis in urology department at Zagazig university hospitals from July 2016 till December 2018. Patients with previous lymphadenectomy, radiotherapy, non-urothelial tumor, advanced disease and not fit for MRI are excluded. MR imaging was performed with a 1.5-T Philips Achieva system class II by using a pelvic phased-array coil with the patient in supine position. MR imaging examination included T2WI, DWI and T1WI without contrast. ADC maps were formed automatically by the device, circular regions of interest (ROIs) were set at different points of lymph nodes. ADC value was obtained with $b$ values 500 and $1000 \mathrm{~s} / \mathrm{mm} 2$. The ADC values are expressed in square millimeters per second.

Every patient was consented after detailed information about the procedure. Approvals was obtained from the ethical committee in faculty of medicine Zagazig University and from patients included in the study.

\section{RESULTS}

33 Patients with MIBC enrolled in this study. Age was distributed as $60.72 \pm 5.67$. They were 27 males and 6 females. 14 patients with positive lymph nodes, they account for $42,4 \%$ of patients. The association and agreement between clinical staging by DW-MRI and pathologic staging was more significant than MRI association and agreement table 1, 2. The overall sensitivity of DWI was $85.7 \%$ while the specificity was $94.7 \%$. However, in conventional MRI the sensitivity was $64,3 \%$ and the specificity was $84.2 \%$ table 3 .

\section{Demographic datat of the patients:}

Table 1: Age distribution among studied group $(N=33)$

\begin{tabular}{|l|l|}
\hline Mean \pm SD & AGE \\
\hline Median (Range) & $60.72 \pm 5.67$ \\
\hline
\end{tabular}

Age was distributed as $60.72 \pm 5.67$

Table 2: Sex distribution among studied group

\begin{tabular}{|l|l|l|l|}
\hline Sex & Female & N & $\%$ \\
\hline & Male & 27 & 18.1 \\
\hline & Total & 33 & $\mathbf{1 0 0 . 0}$ \\
\hline
\end{tabular}

Female accounts for $18.1 \%$ of patients

Table 3: Association and agreement between clinical staging by DW-MRI and pathologic staging

\begin{tabular}{|c|c|c|c|c|c|c|c|c|c|}
\hline & \multicolumn{3}{|l|}{ Grade } & \multirow[t]{2}{*}{ Total } & \multirow[t]{2}{*}{$\mathrm{X}^{2}$} & \multirow[t]{2}{*}{$\mathbf{P}$} & \multirow{2}{*}{$\begin{array}{l}\text { KAPPA } \\
\text { AGREEMENT }\end{array}$} \\
\hline & & & ZERO & ONE & TWO & & & & \\
\hline \multirow{6}{*}{$\begin{array}{l}\text { Grade } \\
\text { DWI }\end{array}$} & \multirow[t]{2}{*}{ ZERO } & $\mathrm{N}$ & 15 & 4 & 0 & 19 & \multirow[t]{6}{*}{13.29} & \multirow[t]{6}{*}{$0.01 *$} & \multirow[t]{6}{*}{0.33} \\
\hline & & $\%$ & $78.9 \%$ & $44.4 \%$ & $0.0 \%$ & $57.6 \%$ & & & \\
\hline & \multirow[t]{2}{*}{ ONE } & $\mathrm{N}$ & 3 & 4 & 5 & 12 & & & \\
\hline & & $\%$ & $15.8 \%$ & $44.4 \%$ & $100.0 \%$ & $36.4 \%$ & & & \\
\hline & \multirow[t]{2}{*}{ TWO } & $\mathrm{N}$ & 1 & 1 & 0 & 2 & & & \\
\hline & & $\%$ & $5.3 \%$ & $11.1 \%$ & $0.0 \%$ & $6.1 \%$ & & & \\
\hline \multirow{2}{*}{\multicolumn{2}{|c|}{ Total }} & $\mathrm{N}$ & 19 & 9 & 5 & 33 & & & \\
\hline & & $\%$ & $100.0 \%$ & $100.0 \%$ & $100.0 \%$ & $100.0 \%$ & & & \\
\hline
\end{tabular}

Significant association and agreement 
Table 4: Association and agreement between clinical staging by MRI and pathologic staging

\begin{tabular}{|c|c|c|c|c|c|c|c|c|c|}
\hline & \multicolumn{3}{|l|}{ Grade } & \multirow[t]{2}{*}{ Total } & \multirow[t]{2}{*}{$\mathrm{X}^{2}$} & \multirow[t]{2}{*}{$\mathbf{P}$} & \multirow{2}{*}{$\begin{array}{l}\text { Kappa } \\
\text { agreement }\end{array}$} \\
\hline & & & ZERO & ONE & TWO & & & & \\
\hline \multirow[t]{4}{*}{ Grade MRI } & \multirow[t]{2}{*}{ ZERO } & $\mathrm{N}$ & 16 & 3 & 3 & 22 & \multirow[t]{4}{*}{7.23} & \multirow[t]{4}{*}{$0.027 *$} & \multirow[t]{4}{*}{0.36} \\
\hline & & $\%$ & $84.2 \%$ & $33.3 \%$ & $60.0 \%$ & $66.7 \%$ & & & \\
\hline & \multirow[t]{2}{*}{ ONE } & $\mathrm{N}$ & 3 & 6 & 2 & 11 & & & \\
\hline & & $\%$ & $15.8 \%$ & $66.7 \%$ & $40.0 \%$ & 33.3\% & & & \\
\hline \multirow[t]{2}{*}{ Total } & & $\mathrm{N}$ & 19 & 9 & 5 & 33 & & & \\
\hline & & $\%$ & $100.0 \%$ & $100.0 \%$ & $100.0 \%$ & $100.0 \%$ & & & \\
\hline
\end{tabular}

Significant association and agreement

The association and agreement between clinical staging by DW-MRI and pathologic staging was more significant than MRI association and agreement.

Table 5 : Senstivity and specificity of DW_MRI and conventional MRI

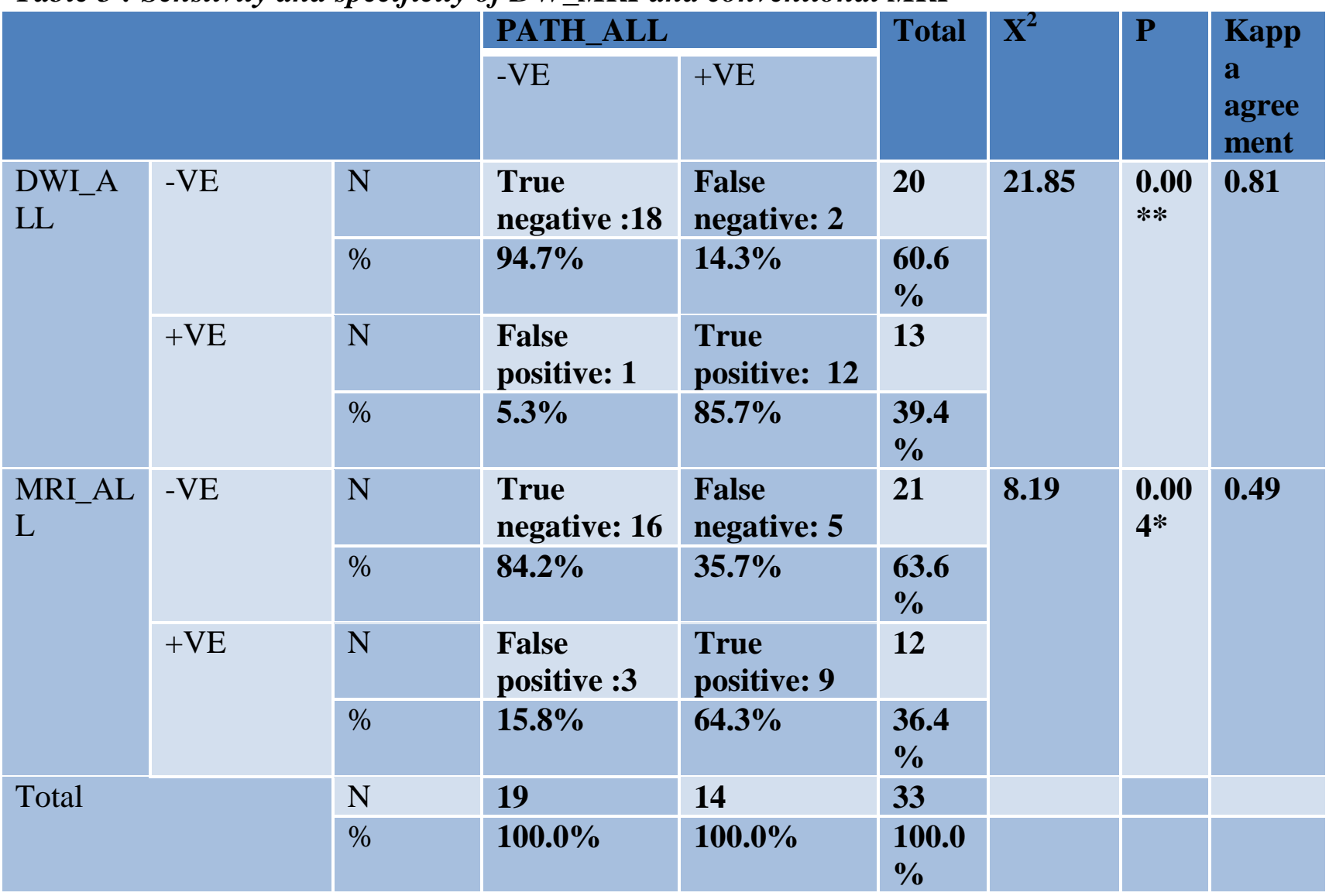

\section{Validity}

\begin{tabular}{|l|l|l|} 
& Sensitivity & Specificity \\
\hline DWI & $85.7 \%$ & $94.7 \%$ \\
\hline MRI & $64.3 \%$ & $84.2 \%$ \\
\hline
\end{tabular}




\section{DISCUSSION}

CT and MRI are usually used for LN staging, and they depend on dimensional criteria only. (99) Conventional MRI has a limited ability to differentiate between malignant from benign lymphadenopathy. The sensitivity of MRI may be as low as $24 \%$ only depending on size criterion. [7] Aljabery et al., [8] study PET CT on 54 patients with bladder cancer, the sensitivity of PET CT was as low as conventional CT. The sensitivity was $41 \%$. DW-MRI is a noninvasive technique which depends on biologic behavior of tissue rather than dimensional criteria. ADC values reflect degree of tissue cellularity so; it can differentiate inflammatory from malignant lymph nodes [9]. In the current study the overall sensitivity of DWI was $85.7 \%$ while the specificity was $94.7 \%$. Many studies show results comparable to our results. Papalia et al., [10] evaluated DW-MRI on 36 patients with bladder cancer who underwent radical cystectomy. The sensitivity was $76.4 \%$. while the specificity of DWI was $89.4 \%$. Eiber et al., [11], Park et al., [12] and Rechichi et al., [13] found the sensitivity of DW-MRI range from $74 \%-98.3 \%$ while specificity range from $74.0 \%-98.3 \%$. Also, lymph node staging in bladder cancer is important prognostic factor so, in patients whom trimodal therapy was decided, there is no lymph node staging. From here the need for more accurate imaging system for diagnosing pelvic lymph node metastasis has been raised.

\section{CONCLUSION}

Diffusion weighted MRI is a noninvasive technique with high accuracy, sensitivity and specificity in detecting lymph node metastasis. It is a safe modality in renal impairment patients. So, it is recommended as clinical staging tool in bladder cancer patients.

\section{Declaration of interest}

The authors report no conflicts of interest. The authors alone are responsible for the content and writing of the paper.

Funding information: None declared

\section{REFERENCES}

1. Ferlay J, Shin HR, Forman D, Mathers C, Parkin DM. GLOBOCAN 2008, Cancer incidence and mortality worldwide: IARC Cancer BaseNo. 10[Internet].Lyon,
France: International Agency for research on cancer; 2010

2. Shariat SF, Palapattu GS, Karakiewicz PI, et al 2007, 'Discrepancy between clinical and pathologic stage: impact on prognosis after radical cystectomy. Eur Urol; vol. 51, pp. 137-51, discussion 149-51.

3. McMahon CJ, Rofsky NM, Pedrosa I 2010,' Lymphatic metastases from pelvic tumors: anatomic classification, characterization, and staging'. Radiology, vol. 254, pp. 31-46.

4. Fleischmann A, Thalmann GN, Markwalder R, et al 2005, ' Extracapsular extension of pelvic lymph node metastases from urothelial carcinoma of the bladder is an independent prognostic factor'. J Clin Oncol, vol. 23, no. 23, pp. 58-65.

5. Gianluca Giannarini, Giusseppe Petralia,Harriet C 2012, 'Potential and Limitations of Diffusion-Weighted Magnetic Resonance Imaging in Kidney, Prostate, and Bladder Cancer Including Pelvic Lymph Node Staging: A Critical Analysis of The Literature' European Urology vol. 60. pp. 326-340.

6. Eiber M, Beer AJ, Holzapfel K, Tauber R, Ganter C, Weirich G, et al 2010, Preliminary results for characterization of pelvic lymph nodes in patients with prostate cancer by diffusion-weighted MRimaging'. Invest Radiol,vol. 45pp. 15-23

7. Grubnic S, Vinnicombe SJ, Norman AR, Husband JE. MR evaluation of normal retroperitoneal and pelvic lymph nodes. ClinRadiol 2002; 57:193-200.

8. Firas Aljabery, Gunnar Lindblom, Susann Skoog, Ivan Shabo, Hans Olsson, Johan Rosell et al. PET/CT versus conventional $\mathrm{CT}$ for detection of lymph node metastases in patients with locally advanced bladder cancer BMC Urology (2015) 15:87

9. Gianluca Giannarini, Giuseppe Petralia, Harriet C. Thoeny, Potential and Limitations of Diffusion-Weighted Magnetic Resonance Imaging in Kidney, Prostate, and Bladder Cancer Including Pelvic Lymph Node Staging: A Critical Analysis of the Literature Eur Urol.2012 feb;61(2):326-40.

10. Simone G, Papalia R, Ferriero M, Guaglianone S, Castelli E, Collura D et al. Stage-specific impact of extended versus standard pelvic lymph node dissection in radical cystectomy. Int J Urol 2013 Apr; 20(4):390-7. 
11. Eiber M, Beer AJ, Holzapfel K, Tauber R, Ganter C, Weirich G, et al 2010, Preliminary results for characterization of pelvic lymph nodes in patients with prostate cancer by diffusion-weighted MRimaging'. Invest Radiol,vol. 45pp. 15-23

12. Park SO, Kim JK, Kim KA, Park BW, Kim N, Cho $\mathrm{G}$ et al. Relative apparent diffusion coefficient: determination of reference site and validation of benefit for detecting metastatic lymph nodes in uterine cervical cancer. J Magn Reson Imaging2009;29(2):383-390.

13. Rechichi G, Galimberti S, Oriani M, Perego P, Valsecchi MG, Sironi $\mathrm{S}$. ADC maps in the prediction of pelvic lymph nodal metastatic regions in endometrial cancer. Eur

To Cite This Article: Mohammed SE*, Khaled MA, Hossam MA, Osama KK and Alaa BE. Lymph Node Staging In Bladder Cancer: Role Of Diffusion Weighted Magnetic Resonant Imaging Compared To Histopathology.ZUMJ 2019;25(6);835-839.DOi: 10.21608/zumj.2019.11025.11420. 